\title{
F-REGION IONIZATION AND HEATING DURING MAGNETIC STORMS
}

\author{
S. CHANDRA \\ J. R. HERMAN
}

SEPTEMBER 1968

FSFC GODDARD SPACE FLIGHT CENTER GREENBELT, MARYLAND

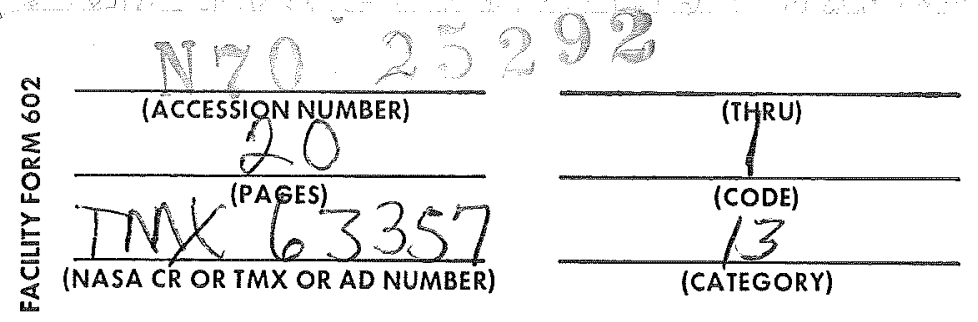




\title{
F-REGION IONIZATION AND HEATING DURING MAGNETIC STORMS *
}

\author{
by \\ S. Chandra and J. R. Herman \\ Laboratory for Space Sciences \\ NASA-Goddard Space Flight Center \\ Greenbe1t, Maryland
}

ABSTRACT

The continuity and heat conduction equations for electrons, ions and neutral species are solved simultaneously from the viewpoint of studying the F-region magnetic storm behavior. It is shown that many of the observed changes in the F-region during the main phase of a magnetic storm can be successfully explained by assuming a decrease in oxygen concentration at the turbopause level. The specific changes in neutral composition, electron density, and electron, $\therefore$ ion , and neutral temperatures during magnetic storms are discussed for different solar conditions.

*To be published in PLANETARY AND SPACE SCIENCE 
Introduction

The storm time morphology of the bottomside F-region has been extensively studied during the past three decades [see Obayashi (1964) for detailed references]. The detailed behavior of the storm time F-region cannot be described in a simple way, since it depends upon the phase and time of the storm as we1l as the location of the observing station. However, the nearly universal features of a magnetic storm are a worldwide decrease in foF2 (up to 50 percent) and the increase in the height of the electron density maximum (up to $100 \mathrm{~km}$ ). The electron density distribution in the topside region during disturbed conditions has been studied only recently [Evans (1965), Reddy et.al (1967), Hibberd and Ross (1967), Rao (1968), and Bauer and Krishnamurthy (1968)]. Here again, though the detailed behavior depends on the height, location and phase of the storm, in general the electron density rises at all heights from about $1.00 \mathrm{~km}$ above the $\mathrm{F} 2$ peak. In addition, the total electron content decreases in a manner similar to $n_{m} F 2$.

Since the satellite drag data has revealed a worldwide enhancement in the neutral density and neutral temperature (the latter derived from the density data by comparison with an atmospheric model) during magnetic disturbances (Jacchia et.a1. 1967) it was considered likely that the depletion in $n_{\mathrm{m}}$ F2 may be due to enhancement in the upper atmosphexic temperature. The actual heating could be caused by one of the several mechanisms: hydromagnetic waves (Dessler 1965), heat conduction waves (Volland 1967) and Joule dissipation of the ring current (Cummings and Dessler, 1967).

Garriot and Rishbeth (1963) and Thomas (1966) argued on the basis of solutions to the electron density continuity equation that the decrease in $n$ F2 caused by atmospheric heating 
camot be more than 25 percent and hence not sufficient to account for the large decrease in density actually observed. Several theories exist for the F-region disturbances. The electrodynamic drift-theory, (Martyn,1954), the increase in dissociative recombination rate (Seaton 1956), the flow of ionization between ionosphere and magnetosphere through hydromagnetic pumping (Piddington 1964) and the loss of thermal plasma through inflation of the magnetosphere and through local "energization" (Bauer and Krishnamurthy, 1968). Many of these ideas have certain merits since they succeed in explaining the general storm time behavior of the Fregion to varying degrees of approximation. The difficulty comes, however, when an attempt is made to account for the temperature and density variations of both the ionized and neutral constituent throughout the altitude $x$ ange of the F-region. Moreover, many of these ideas are qualitative and it is difficult to relate them to the observational data in a quantitative manner. We feel, however, that the temperature effects during the disturbed condition are quite important in spite of the difficulties encountered by Garriot and Rishbeth (1965) and Thomas (1966). In this paper, we shall attempt to examine this aspect of the Feregion magnetic storm.

The Effect of Changes in the Lower Boundary

In the accompanying paper [Herman and Chandra 1968; to be referced to as paper I] the effects of solar EUV on density and temperature of both the neutral and ionized constituents were discussed. It was shown that in solving the equations of contiauity and heat transport, the boundary values of the neutral constituent canot be assumed invariant throughout the solgr cycle. In discussing the magnetic storm problem, a similar 
situation arises. It is reasonable to assume that the solar EUV flux maintains its pre-storm values, but there is no reason to believe that the lower boundary densities remain invariant during the disturbed period. The neutral composition, particularly atomic oxygen, in the mesosphere and the lower thermosphere are strongly controlled by eddy diffusion, transport, and chemical processes [Colegrove et. al. 1966, Shimazaki 1967, Maeda and Aikin 1968, Hesstvedt 1968]. In the high latitudes these processes can be modified by the precipitation of energetic electrons and the heat dissipation due to ring current. Hines (1965) believes that some of the energy deposited in the auroral region during magnetic storms can be transported to the lower latitudes by means of gravity waves. While it is difficult to estimate the composition changes resulting from these mechanisms, it is reasonable to postulate that the composition in the lower atmosphere does change during magnetic storms particularly in the middle and high latitudes. Evidence of such changes in composition can be inferred from the enhancement in the intensity of the airglow during magnetic storms [Truttse, 1968; Weil1 and Glaume, 1967]. It will be shown in the following that many of the important features of the F-region magnetic storm can be described from the simultaneous solutions of the equations of continuity and heat transport for both the neutral and ionized constituents by making suitable changes in the lower boundary.

The Equations of Continuity and Heat Conduction

The equations of continuity and heat transport and their method of solution have been discussed in paper $I$. In the following, only an outline is presented for ready reference. Equation of continuity for electron density:

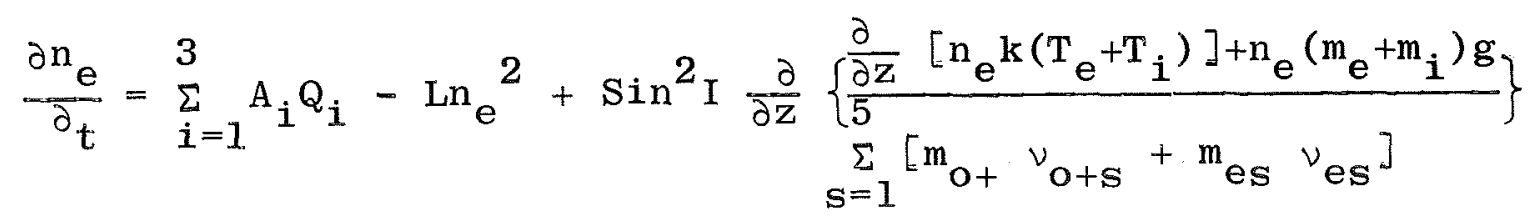


Heat conduction equation for electrons:

$$
\mathfrak{n}_{e} k^{k} C_{v e} \frac{\partial T_{e}}{\partial t}-\operatorname{Sin}^{2} I \frac{\partial}{\partial z}\left[K_{e} \frac{\partial T_{e}}{\partial z}\right]=Q_{e}-\sum_{S} L_{e s}-L_{e i}
$$

Heat conduction equation for ions:

$$
\dddot{n}_{e} k^{k i} \frac{\partial T_{i}}{\partial t}-\operatorname{Sin}^{2} I \frac{\partial}{\partial z}\left[K_{i} \frac{\partial T_{i}}{\partial z}\right]=L_{e i}-L_{i}
$$

Heat conduction for neutral constituents:

$$
n_{i} k \frac{\partial T_{n}}{\partial z}-\frac{\partial}{\partial z}\left[K_{n} \frac{\partial T_{n}}{\partial z}\right]=Q_{n}+\Sigma L_{e s}+L_{i}-L_{n}
$$

The various neutral constituents $\left(\mathrm{N}_{2}, \mathrm{O}_{2}, 0, \mathrm{H}_{\mathrm{e}}\right.$, and $\left.\mathrm{H}\right)$ are assumed to be in diffusive equilibrium

$$
N_{i}=\frac{N_{i}\left(z_{1}\right) T_{n}\left(z_{1}\right)}{T_{n}(z)} \exp \left\{-\int_{z_{1}}^{z} \frac{m_{i} g\left(z^{\prime}\right)}{k T_{n}\left(z^{\prime}\right)} d z^{\prime}\right\}
$$

\section{Discussion}

The definition of the terms in equations $1-5$ and their numerical values are exactly the same as in paper $I$ as are their method of solution. Here we have characterized the storm time conditions by a decrease in the oxygen concentration at the turbopause level as compared to the prerstorm value. As in paper I, this level has been assumed to be $100 \mathrm{~km}$. It may be pointed out 
that in many of the atmospheric models, the turbopause level is generally assumed to be between $120-130 \mathrm{~km}$. Our present choice has been guided by the recent experimental results (Shaeffer 1967; Hartman et.at. 1967) which show this level to be less than $110 \mathrm{~km}$. The general conclusion of this paper is not dependent on the exact knowledge of the reference boundary values.

The numerical results of the calculations are shown in Figure 1-3 which show the steady state height profiles of the densities and temperatures for both the neutral and ionized constituents corresponding to the various phases of the solar cycle. We have chosen three values of EUV fluxes, $1.00 \mathrm{HF}$, $1.30 \mathrm{HF}$ and $1.60 \mathrm{HF}$, as representative of different phases of solar activity (HF denotes the flux values in the spectral range of 10-1027A as given by Hinteregger et.al. (1965)). All the calculations relate to the magnetic dip angle $70^{\circ}$ and solar zenith angle $39^{\circ}$, the latter corresponding to approximately equinoctial noon condition at mid-latitudes.

Figure (1-a) shows the density profiles for $\left[\mathrm{N}_{2}\right],\left[\mathrm{O}_{2}\right]$ and [0] corresponding to $1.30 \mathrm{HF}$. The boundary values assumed for the five neutral constituents for the quiet and disturbed condition are as given in the following table.

\section{TABLE 1}

QUIET

DISTURBED

$\begin{array}{lll}\mathrm{N}_{2} & 4.65 \times 10^{12} / \mathrm{cm}^{3} & 4.65 \times 10^{12} / \mathrm{cm}^{3} \\ 0_{2} & 1.25 \times 10^{12} / \mathrm{cm}^{3} & 1.25 \times 10^{12} / \mathrm{cm}^{3} \\ 0 & 1.00 \times 10^{12} / \mathrm{cm}^{3} & 5.00 \times 10^{11} / \mathrm{cm}^{3} \\ \mathrm{H}_{\mathrm{e}} & 2.50 \times 10^{8} / \mathrm{cm}^{3} & 2.50 \times 10^{8} / \mathrm{cm}^{3} \\ \mathrm{H} & 1.00 \times 10^{5} / \mathrm{cm}^{3} & 1.00 \times 10^{5} / \mathrm{cm}^{3}\end{array}$


It may be noted that the only difference assumed in the quiet and disturbed condition is the reduction in oxygen concentration by 50 percent compared to its pre-storm value at the reference level. The values assumed for the two cases are quite arbitrary and have been adopted:for illustration only. The density and temperature profiles as a result of this decrease are shown in Figures 1-a, 1-b. The main points of these Figures can be summarized in the following:

1. The isothermal neutral temperature increases from about $900^{\circ} \mathrm{K}$ to $1100^{\circ} \mathrm{K}$ - an increase of about $200^{\circ} \mathrm{K}$ (Figure 1-b).

2. There is a general increase in $\left[\mathrm{N}_{2}\right]$ and $\left[\mathrm{O}_{2}\right]$ values throughout the altitude range corresponding to the increased neutral temperature (Figure 1-2). The helium and hydrogen densities show a similar increase (not shown here for the sake of clarity).

3. The oxygen concentration is less than its premstorm value up to about $300 \mathrm{~km}$ though the difference between the two values $[0]_{Q}-[0]_{D}$ continuously decreases with altitude. At about $300 \mathrm{~km}$ the two drofiles cross over and from there on $[0]_{D}$ continues to be greater than $[0]_{Q}$.

4. Both the electron and ion temperatures show an enhancement by a few hundred degrees compared to the quiet condition. The peak electron temperatures $T_{e} \max _{Q}$ and $T_{e} \max _{D}$ are 2170 and $2479^{\circ} \mathrm{K}$ at 180 and $200 \mathrm{~km}$ respectively.

5. The electron density $n_{e D}$ is less than $n_{e Q}$ up to about $350 \mathrm{~km}$. The two distributions cross over at this altitude. Above $350 \mathrm{~km} \mathrm{n}_{\mathrm{eD}}$ continues to be higher than $\mathrm{n}_{\mathrm{eQ}}$. The maximum decrease in $\mathrm{n}_{\mathrm{eD}}$ is near the height of the maximum. The maximum electron densities $n_{\text {emaxQ }}$ and $n$ emaxD are 
respectively $13.5 \times 10^{5}$ and $6.8 \times 10^{5}$ elect./ $\mathrm{cm}^{3}$ at $260 \mathrm{~km}$ and $310 \mathrm{~km}$. This reflects a decrease of about 50 percent in $n_{\text {emax }}$ and increase in $h_{\max }$ by $50 \mathrm{~km}$.

6. The total electron content $n_{t Q}$ and $n_{t D}$ are $23.2 \times 10^{12} / \mathrm{cm}^{-2}$ and $19.4 \times 10^{12} / \mathrm{cm}^{-2}$. This shows a decrease of about 16 percent.

Figures $2 \mathrm{a}$ and $2 \mathrm{~b}$ show the results corresponding to $1.00 \mathrm{HF}$ which corresponds to low solar activity. The important features of these figures are similar to the ones discussed in the preceeding section though the changes in the disturbed and quiet conditions are not quite the same. The important differences are in $T_{e}$ and $n_{e}$ profiles. The electron temperature shows a transition from a peaked profile to a monotonically increasing profile (Figure $2 \mathrm{~b}$ ). The increase in $\mathrm{T}_{\mathrm{e}}$ is almost by a factor of 2 from about $200 \mathrm{~km}$ onwards. The effect of this considerable increase in $\mathrm{T}_{e}$ is reflected in the $\mathrm{n}_{e}$ profile which shows a rather large gradient above the $\mathrm{F}_{2}$ peak. This abnormal increase in $T_{e}$ should not be interpreted as typical of a mid-latitude storm during low solar activity. The increase is usually associated with the change in the characteristic of the $T_{e}$ profile as was discussed in paper I. In fact, on either side of the transition region the percentage variation in $\mathrm{T}_{\mathrm{e}}$ is rather small.

Figures $3 a$, and $3 b$ show the density and temperature profiles corresponding to $\mathrm{HF}=1.6$. The main features are essentially the same as those shown in Figures $1 \mathrm{a}$ and $1 \mathrm{~b}$. The following table summarizes the overall results of Figure 1, 2 and 3 . 


\begin{tabular}{|c|c|c|c|c|c|c|}
\hline \multirow{2}{*}{$\begin{array}{l}\text { TABLE } 2 \\
\text { Ionospheric } \\
\text { parameters. }\end{array}$} & \multicolumn{2}{|c|}{$\begin{array}{c}\text { LOW } \\
\mathrm{HF}=1.00\end{array}$} & \multicolumn{2}{|c|}{ MEDIUM } & \multicolumn{2}{|r|}{$\mathrm{HIGH}$} \\
\hline & {$[0]=1.00 \times 10^{12} \mathrm{~cm}^{-3}$} & {$[0]=5.0 \times 10^{11}$} & {$[0]=1.0 \times 10^{12}$} & {$[0]=5.0 \times 10^{11}$} & {$[0]=1.0 \times 10^{12}$} & {$[0]=5.0 \times 10^{11} \mathrm{~cm}^{-3}$} \\
\hline 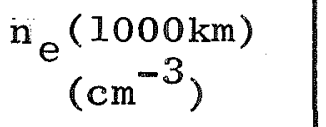 & $8.29 \times 10^{2}$ & $1.33 \times 10^{2}$ & $5.49 \times 10^{3}$ & $1.21 \times 10^{4}$ & $4.29 \times 10^{4}$ & $5.59 \times 10^{4}$ \\
\hline $\begin{array}{c}\mathrm{n}_{\mathrm{e}}^{(500 \mathrm{~km})} \\
\left(\mathrm{cm}^{-3}\right)\end{array}$ & $1.52 \times 10^{4}$ & $6.41 \times 10^{4}$ & $1.2 \times 10^{4}$ & $2.12 \times 10^{5}$ & $7.8 \times 10^{5}$ & $6.62 \times 10^{5}$ \\
\hline$n_{e}(150)\left(\mathrm{cm}^{-3}\right)$ & $2.50 \times 10^{5}$ & $2.23 \times 10^{5}$ & $2.47 \times 10^{5}$ & $2.22 \times 10^{5}$ & $2.22 \times 10^{5}$ & $2.12 \times 10^{5}$ \\
\hline $\mathrm{n}^{\max \left(\mathrm{cm}^{-3}\right)}$ & $8.73 \times 10^{5}$ & $3.26 \times 10^{5}$ & $13.54 \times 10^{5}$ & $6.83 \times 10^{5}$ & $20.34 \times 10^{5}$ & $10.29 \times 10^{5}$ \\
\hline $\mathrm{h} \max (\mathrm{km})$ & 230 & 230 & 260 & 310 & 320 & 380 \\
\hline $\mathrm{n}_{\mathrm{et}}\left(\mathrm{cm}^{-2}\right)$ & $9.75 \times 10^{12}$ & $8.50 \times 10^{12}$ & $23.2 \times 10^{12}$ & $19.4 \times 10^{12}$ & $54.6 \times 10^{12}$ & $36.4 \times 10^{12}$ \\
\hline $\begin{array}{c}\mathrm{T}_{\mathrm{e}}(1000 \mathrm{~km}) \\
\left.\mathrm{q}^{\mathrm{o}} \mathrm{K}\right)\end{array}$ & 1869 & 3829 & 1677 & 1761 & 1629 & 1843 \\
\hline $\begin{array}{c}\mathrm{T}_{\mathrm{e}}(500 \mathrm{~km}) \\
\left({ }^{\mathrm{O}} \mathrm{K}\right)\end{array}$ & $1532 \ldots$ & 3552 & 1244 & 1338 & 1289 & 1541 \\
\hline $\mathrm{T}_{\mathrm{e}}^{\max \left({ }^{\circ} \mathrm{K}\right)}$ & 2022 & 3829 & 2170 & 2479 & 2390 & 2723 \\
\hline $\mathrm{h}\left(\mathrm{T}_{\mathrm{e}} \max \right)(\mathrm{km})$ & 160 & 1000 & 180 & 200 & 190 & 220 \\
\hline $\mathrm{T}_{\mathrm{i}}(1000 \mathrm{~km}(\mathrm{~K})$ & 1313 & 2123 & 1438 & 1560 & 1559 & 1727 \\
\hline $\begin{array}{c}\mathrm{T}_{\mathrm{n}}(1000 \mathrm{~km}) \\
\left({ }^{\mathrm{O}} \mathrm{K}\right)\end{array}$ & 650 & 787 & 908 & 1096 & 1255 & 1472 \\
\hline $\begin{array}{l}c_{v e} \iint_{e}{ }_{e} d z \\
\left(\text { ergs.cm }{ }^{-2}\right)\end{array}$ & 2.38 & 5.60 & 5.60 & 6.37 & 15.60 & 13.30 \\
\hline
\end{tabular}


Table 2 shows some numerical examples of the effects of decreasing oxygen concentration on the various ionospheric parameters. These changes are consistent with the commonly known changes in the F-region during magnetic storms in the middle and high magnetic latitudes. Thus, our calculations show reasonable agreement with the observed enhancement of electron density in the topside region of the order of 100 percent [King et.al., (1967) Bauer and Krishnamurthy (1968)] and the depression in $n_{m} F_{2}$ up to 50 percent (Obayashi 1964). The increase in the height of the $\mathrm{F}_{2}$ maximum, electron, ion, and neutral temperatures and neutral density, and the decrease in total electron content as shown in Table 2 [and Figure 1-3], are in general agreement with the observational data [Evans 1965, Jacchia et.al., Hibberd and Ross, 1967]. We cannot, of course, explain the complex changes in the F-region through the various phases of magnetic storms based on steady state solutions presented in this paper. For a complete understanding of the problem it will be necessary to consider the solutions of the time dependent equations along with the time dependent boundary values appropriate for storm time conditions.

In our calculation we only decreased the oxygen concentration and the other changes followed accordingly. The result would have been the same if instead of decreasing [0] at the turbopause level, we would have lowered the level itself. Further, we did not change the relative values of [0] with the change in solar activity, for the sake of simplicity. The main purpose of this paper is to illustrate the result of this change rather than to obtain a quantitative agreement between the theoretical and observational results. 
Conclusion

In this paper we started with the assumption that the turbopause level of oxygen is decreased during the main phase of the magnetic storm in the middle and high magnetic latitudes resulting in the decrease of [0] in the lower thermosphere. The general behavior of the F-region during magnetic storms can be satisfactorily explained with this assumption. Consequently the decrease in foF2 and the increase in the neutral temperature and density are the results of redistribution of [0].

The physical implications of the changes in oxygen concentration is easy to understand if it is realized that the atmospheric neutral tempexature is essentially controlled by the relative magnatude of heat production and heat loss in the lower thermosphere. The thermal conduction helps only to establish isothermal temperatures at high altitudes. The electron density distribution is controlled by the photo-chemical processes in the lower F-region and photo-diffusive processes in the upper F-region. Since oxygen provides an important heat sink for the neutral constituents in the lower thermosphere, a reduction in its value results in the reduction of the loss term in the neutral temperature equation. The contribution to the heat production term is also reduced, though not to the same extent as the loss term. Consequently, there is a net increase in the total heat input to the neutral gas, and hence, an increase in neutral temperature. The various neutral constituents, which are assumed to be in diffusive equilibrium, are also increased corresponding to the new higher temperature. In the case of [0], this increase is naturally reflected only in the higher altitudes [Figures 1-a, 2-a, and 3-a]. The effect of this redistribution is to increase the electron 
loss term [due to its direct dependence on $\left[\mathrm{N}_{2}\right]$ and $\left.\left[\mathrm{O}_{2}\right]\right]$ and to decrease the electron production term [due its direct dependence on [0]] in the bottomside F-region. The net effect then is an overall reduction in electron density. In the topside region the situation is somewhat different. Here the electron production term is increased and the diffusion coefficient is decreased. Both these changes have a net effect of increasing the electron density.

Unfortunately, the observational data on the neutral composition in the lower atmosphere during magnetic storms are almost non-existent. Recently, Reber (private communication) from his mass spectrometer experiment aboard Explorer XXXII, found some evidence of composition changes during magnetic storms. His observations revealed a decrease in [0] by 45 percent and increase in $\left[\mathrm{N}_{2}\right]$ by a factor of 2 at $285 \mathrm{~km}$ and in the latitude (geographic) range of $36^{\circ}-46^{\circ}$. This observation is in general agreement with our result. Clearly many more observations of this kind are needed particularly in the lower thermosphere and mesosphere for a direct experimental verification of our hypothesis. It is evident, however, from the present study that the changes in the Frregion are closely related to the composition changes in the lower atmosphere. An understanding of the photo-chemical and dynamical processes effecting this region both during quiet and disturbed conditions is therefore of considerable importance in understanding the storm time behavior of the F-region. 


\section{REFERENCES}

Bauer, S. J. and B. V. Krishnamurthy, 1968, Planet. \& Space Sci. 16,653 .

Colegrove, F. D., F. S. Johnson and W. B. Hanson, 1966, J. Geophys. Res. 71,2227 .

Cummings, W. D. and A. J. Dessler, 1967, J.Geophys. Res. 72, 257.

Dessler, A. J., 1965, Space Res. $1,119$.

Evans, J. V., 1965, J. Geophys.Res. 70, 2726.

Garriott, O。K。 and H. Rishbeth, 1963, Planet. Space Sci. 11, 587.

Hartmann, G. K. Mauersberger and D. Muller, 1968, Space Res. VIII, 940 。 Hesstvedt, E。, 1968, Geophys. Publ。Geophysica Norvegia, Vol. 27,

No 4.

Hibberd, F. H. and W. J. Ross, 1967, J. Geophys. Res. 72, 5331 .

Hinteregger, H., L. Hall and G. Schmidtke, 1965, Space Res. V, 1175.

Jacchia, L. G., J. Slowey and F. Verniani, 1967, J. Geophys.

Res. 72,1423 .

King, J.W., K. C. Reed, E. C. Olatunji, 1967, J. Atm. Terr.

Phys. 29, 1355 .

Maeda, K. and A. C. Aikin, 1968, Planet. \& Space Sci. 16371.

Martyn, D. F., 1954, Rep. Ionosph. Japan 8, 11.

Obayashi, T., 1964, Res. in Geophys., Vol. I., H. Odishaw ed.

(MIT, Press) 335 .

Piddington, J. H。, 1964, Planet。\& Space Sci. 12, 553.

Rao, P.B., 1968, J.Geophys. Res. 73, 1661 .

Reddy, B. M., L. H. Brace and J. A. Findlay, 1967, J. Geophys.

Res. $72,2709$.

Schaefer, E。J., 1968, Space Res。VIII, 959.

Shimazaki, T., 1967, J.Atmos.\& Terr. Phys. 29, 723.

Thomas, L., 1966, J. Geophys. Res. 71, 1357.

Truttse, Y。L., 1968, Planet.\& Space Sci., 16, 981.

Volland, H., 1967, J. Geophys. Res. 72, 2831.

Wei11, G. and J.C. Glaume, 1967 Annales de Geophysique, 23, 317. 


\section{FIGURE CAPTIONS}

Figure 1-a.

The altitude variations of $\mathrm{N}_{2}, \mathrm{O}_{2}$ and $\mathrm{O}$ for quiet and disturbed conditions corresponding to $H F=1.3$. The oxygen density variations between 100 to $300 \mathrm{~km}$ have been redrawn in the upper right hand corner for clarity.

Figure 1-b. The altitude profiles of $n_{e}, T_{e}, T_{i}$ and $T_{n}$ for quiet and disturbed conditions corresponding to $\mathrm{HF}=1.30$.

Figure 2-a. The altitude variations of $\mathrm{N}_{2}, 0_{2}$ and 0 for quiet and disturbed conditions corresponding to $\mathrm{HF}=1.0$. The oxygen density variations between 100 to $300 \mathrm{~km}$ have been redrawn in the upper right hand corner for clarity.

Figure 2-b. The altitude profiles of $n_{e}, T_{e}, T_{i}$ and $T_{n}$ for quiet and disturbed conditions corresponding to $\mathrm{HF}=1.0$.

Figure 3-a. The altitude variations of $\mathrm{N}_{2}, \mathrm{O}_{2}$ and 0 for quiet and disturbed conditions corresponding to $\mathrm{HF}=1.6$. The oxygen density variations between 100 to $300 \mathrm{~km}$ have been redrawn in the upper right hand corner for clarity.

Figure 3-b. The altitude profiles of $n_{e}, T_{e}, T_{i}$ and $T_{n}$ for quiet and disturbed conditions corresponding to $\mathrm{HF}=1.6$. 


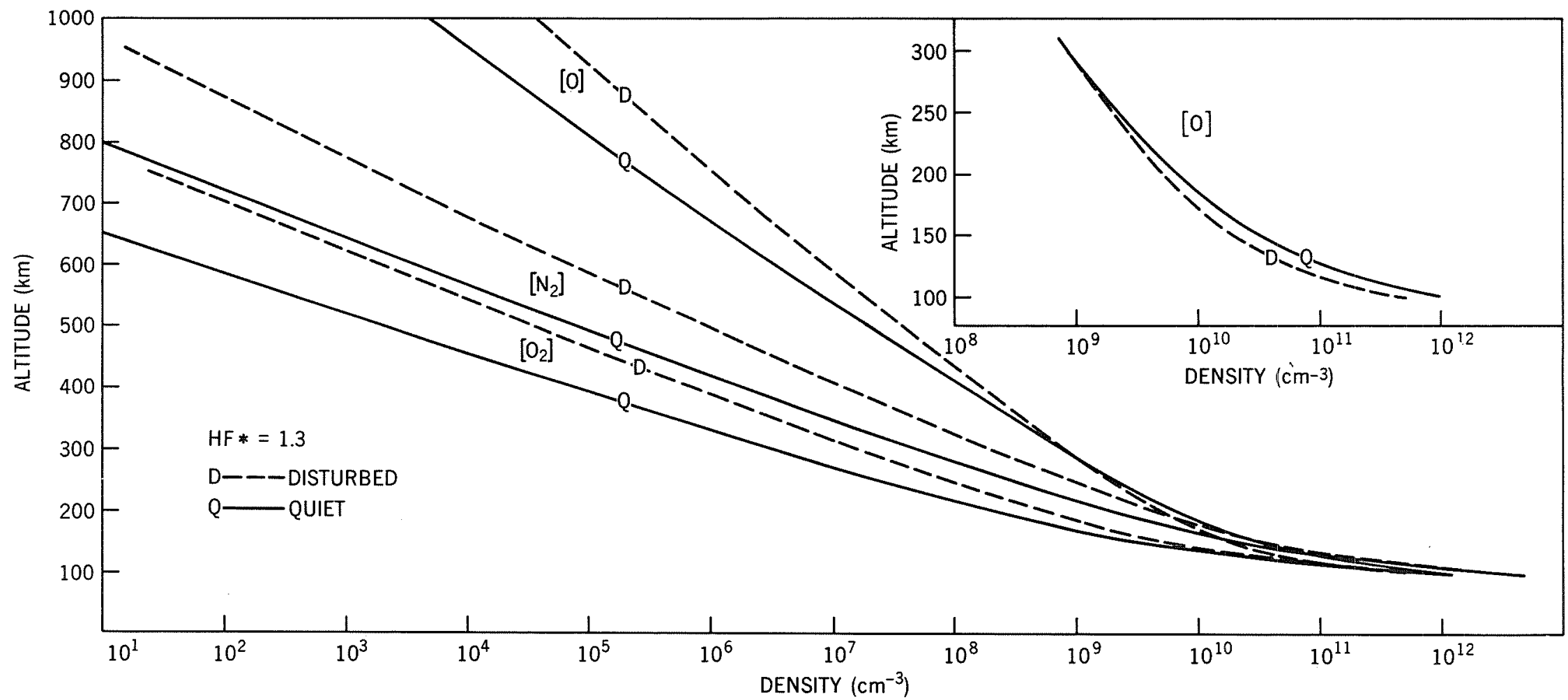

Figure 1-a. 


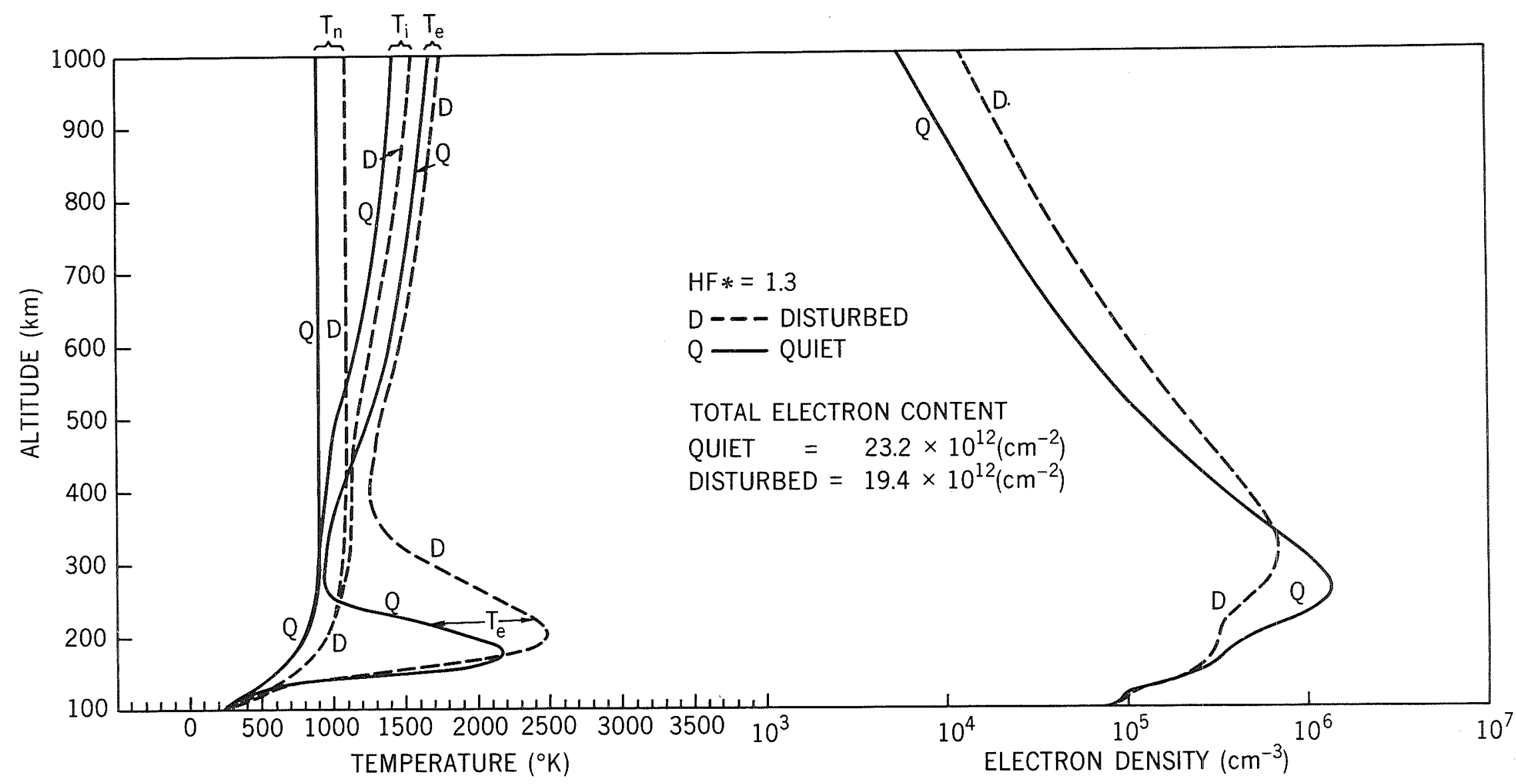

Figure 1-b. 


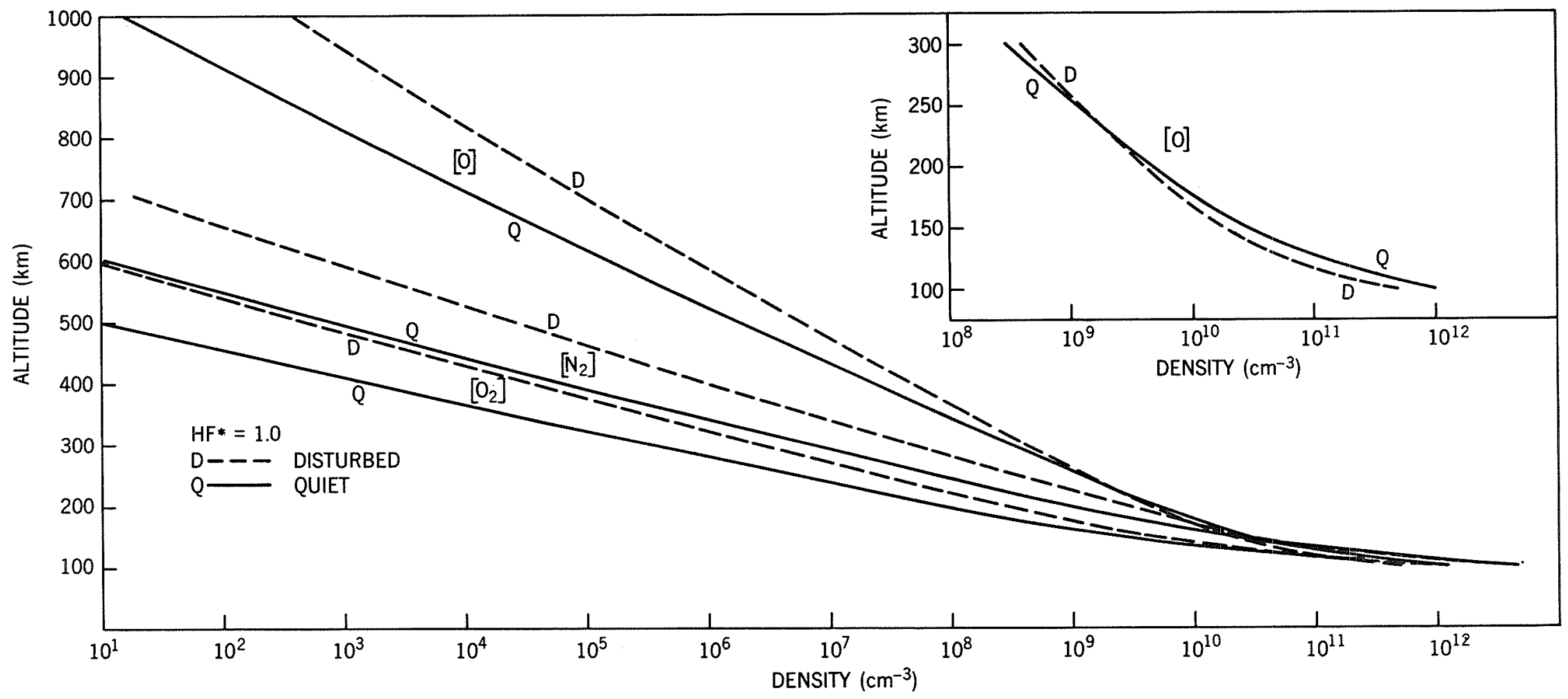

Figure 2-a. 


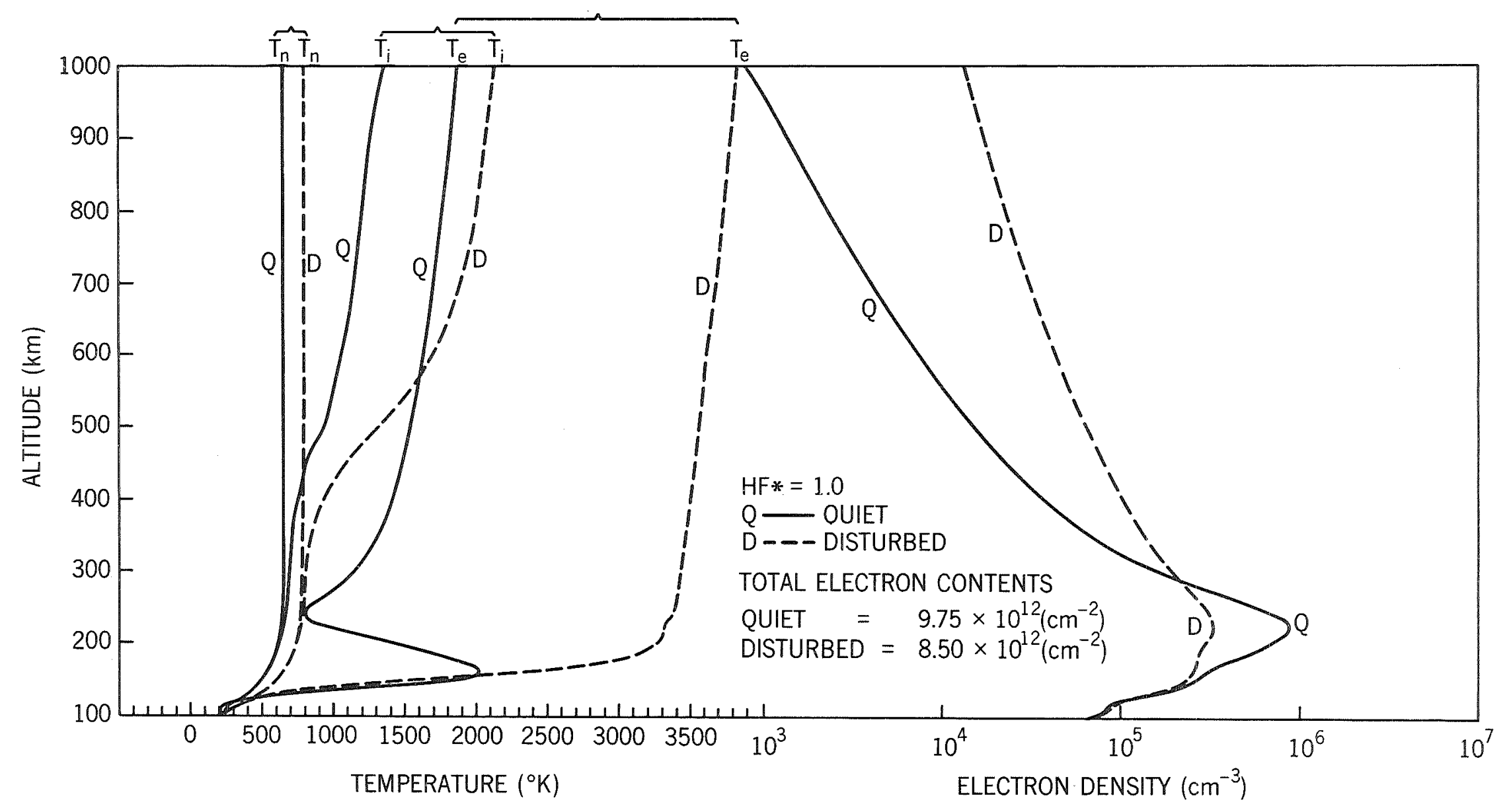

Figure 2-b. 


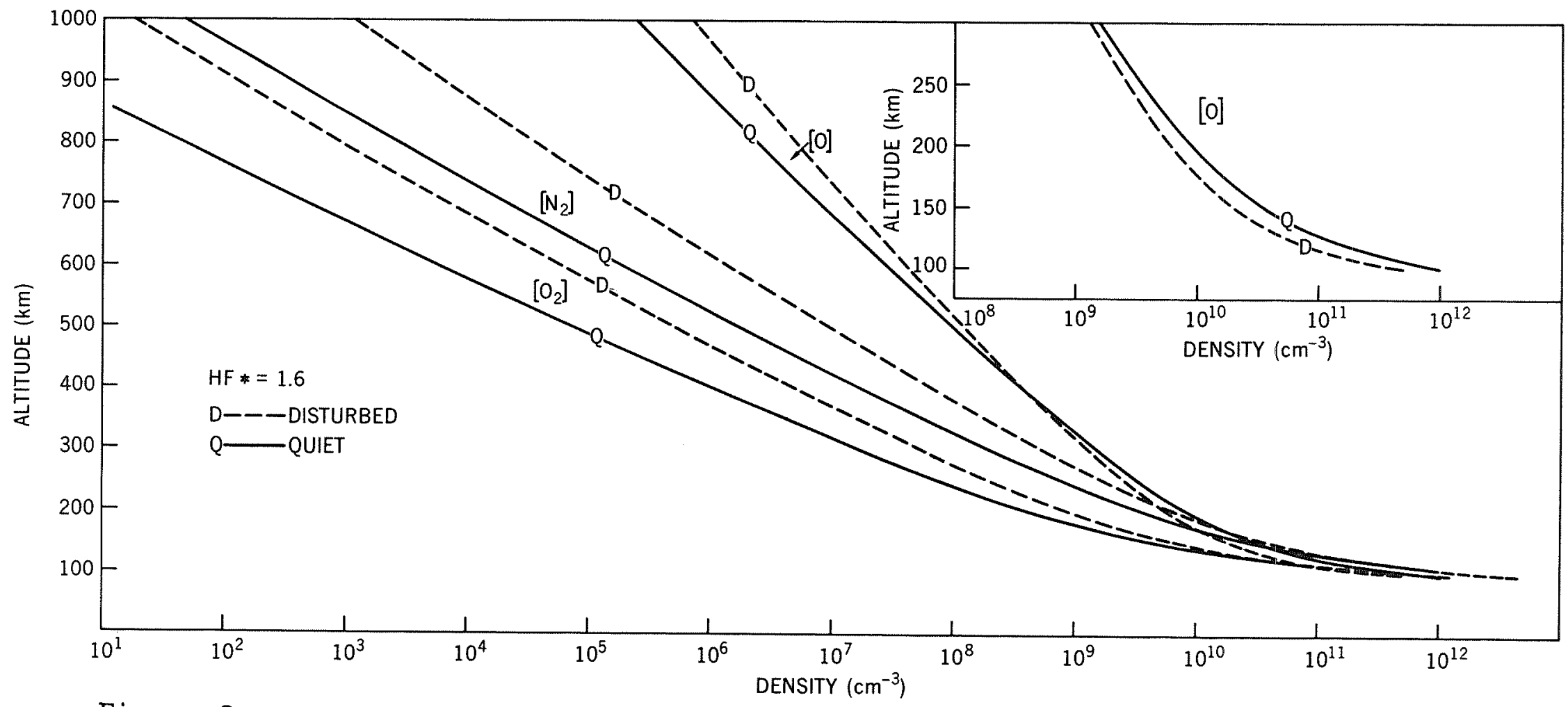

Figure 3-a. 


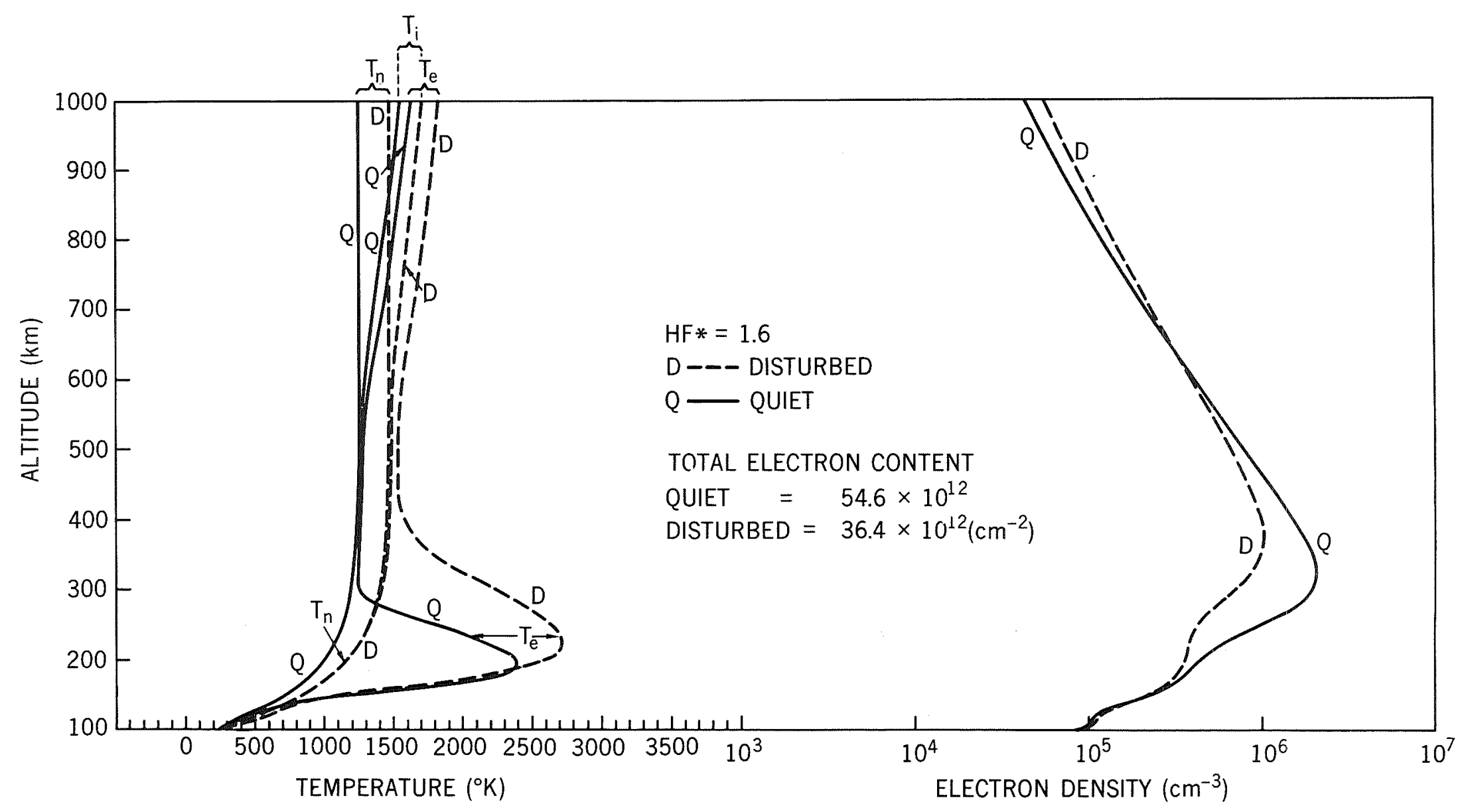

Figure 3-b. 